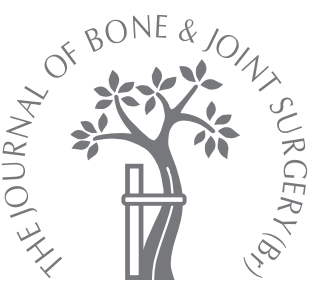

K. Sairyo,

T. Sakai,

N. Yasui

From the University

of Tokushima,

Tokushima, Japan

\title{
Conservative treatment of lumbar spondylolysis in childhood and adolescence
}

\author{
THE RADIOLOGICAL SIGNS WHICH PREDICT HEALING
}

K. Sairyo, MD, PhD,
Associate Professor
T. Sakai, MD, Assistant
Professor
N. Yasui, MD, PhD, Professor
and Chairman
Department of Orthopaedics
University of Tokushima School
of Medicine, 3-18-15,
Kuramoto, Tokushima 770-
8503, Japan.
Correspondence should be sent
to Professor K. Sairyo; e-mail:
sairyokun@ $@$ hotmail.com

(C)2009 British Editorial Society of Bone and Joint Surgery doi:10.1302/0301-620X.91B2. $21256 \$ 2.00$

$J$ Bone Joint Surg $[\mathrm{Br}]$ 2009;91-B:206-9.

Received 8 May 2008; Accepted after revision 25 September 2008

It has been noted that bony union of a pars defect can be achieved in children if they wear a trunk brace. Our aim was to evaluate how the stage of the defect on CT and the presence or absence of high signal change in the adjacent pedicle on T2-weighted MRI were related to bony healing. We treated 23 children conservatively for at least three months. There were 19 boys and four girls with a mean age of 13.5 years ( 7 to 17). They were asked to refrain from sporting activity and to wear a Damen soft thoracolumbosacral type brace. There were 41 pars defects in 23 patients. These were classified as an early, progressive or terminal stage on CT. The early-stage lesions had a hairline crack in the pars interarticularis, which became a gap in the progressive stage. A terminal-stage defect was equivalent to a pseudarthrosis. On the T2-weighted MR scan the presence or absence of high signal change in the adjacent pedicle was assessed and on this basis the defects were divided into high signal change-positive or -negative. Healing of the defect was assessed by CT.

In all, $13(87 \%)$ of the 15 early defects healed. Of 19 progressive defects, only six (32\%) healed. None of the seven terminal defects healed. Of the 26 high signal change-positive defects $20(77 \%)$ healed after conservative treatment whereas none of the high signal change-negative defects did so. We concluded that an early-stage defect on CT and high signal change in the adjacent pedicle on a T2-weighted MR scan are useful predictors of bony healing of a pars defect in children after conservative treatment.

Spondylolysis is the result of a stress fracture of the pars interarticularis. ${ }^{1-3}$ Because it is a fracture, it can, theoretically, unite after conservative treatment if it is identified early before it progresses to pseudarthrosis. It has been reported that bony union can be obtained by wearing a trunk brace such as a Boston brace or a Damen-type soft corset (Fig. 1). Figure 2 shows an example of bony union achieved after conservative treatment in a brace for three months.

Several radiological features have been identified which can predict healing of the pars defect by conservative management. ${ }^{4-6}$ In our retrospective study, we have evaluated two of these, namely, the stage of the defect on CT and high signal changes in the adjacent pedicle on T2-weighted MRI. Based on our results, we propose a strategy for the conservative management of lumbar spondylolysis in children and adolescents.

\section{Patients and Methods}

Between January 2002 and August 2003 we treated conservatively 23 patients (18 boys, 5 girls) with a mean age of 13.5 years
(7 to 17) for spondylolysis. They were asked to refrain from sports and to wear a Damen soft thoracolumbosacral brace. In total, 41 pars defects were treated conservatively. These were classified into early, progressive or terminal stages by CT. ${ }^{4}$ In an early defect, a hairline crack is visible in the pars. It then worsens and becomes a gap in the progressive stage. A terminal-stage defect is a pseudarthrosis.

Each patient had an MRI which included T1- and T2-weighted scans with axial views of the pedicles. These were examined for high signal change. Figure 3 shows the normal appearance of the pedicle on T1- and T2-weighted scans. The signal from cancellous bone is the same in the pedicle as that in the vertebral body.

Figure 4 shows high signal change in the pedicle on a T2-weighted scan. When the pedicle showed high signal change on both the T1- and T2-weighted scans that on the T2-image was interpreted as fatty marrow, and judged to be a false-positive. When the pedicle was of low signal intensity on the T1weighted scan, the high signal change was 


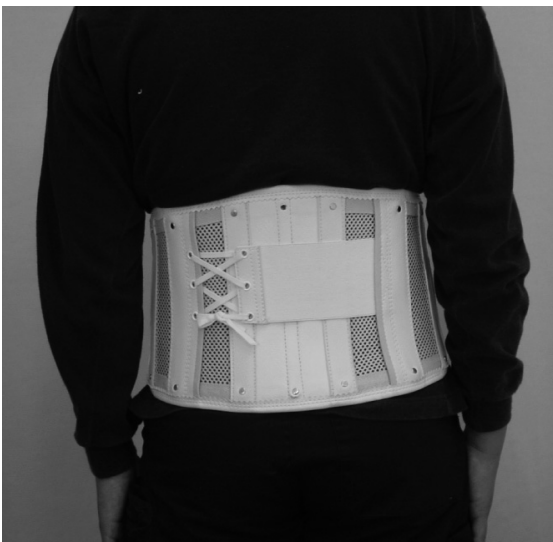

Fig. 1

Photograph showing the Damen-type soft trunk corset used in our study. The dorsal part of the corset is strengthened to restrict lumbar extension.

taken as a true-positive (Fig. 4). The defects were thereby divided into high signal change-positive or -negative. Bony healing of the pars defect was evaluated by CT.

After three months, further CT was performed to assess the extent of bony union. If the pars defect was uniting, the patients were advised not to play sport for another three months. If, however, the defect had become a pseudarthrosis, the terminal stage, they were allowed to resume their previous sporting activities. The chi-squared test was used for all statistical analysis.

\section{Results}

On the basis of the initial CT scan there were 15 early, 19 progressive and seven terminal defects. After conservative treatment, $13(87 \%)$ of the 15 early defects but only six $(32 \%)$ of the 19 progressive defects had healed. None of the seven terminal defects had done so (Table I).

On the initial MR scan, 26 defects were high signal changepositive and 15 were -negative. The high signal change on the T2-weighted scan of all 19 progressive defects was a truepositive. In all, 20 (77\%) of the 26 high signal change-positive defects healed after conservative treatment whereas none of the -negative defects did so (Table II).

Table III correlates the outcome of each group with their CT and MRI findings. Early defects with a positive high signal change healed in $87 \%$ of cases. Progressive defects were divided into two subgroups based on whether the high signal change or MRI was positive or negative. Progressive defects with a positive high signal change healed in $60 \%$ of cases. None of these with a negative high signal change healed. This difference was found to be significant (chi-squared test, $\mathrm{p}<0.05)$. None of the terminal defects healed.

\section{Discussion}

In our study, we investigated the radiological signs which might predict successful bony healing of a pars defect in children and adolescents after conservative treatment. An

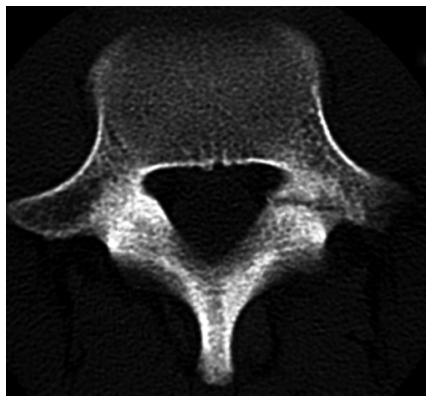

Fig. 2a

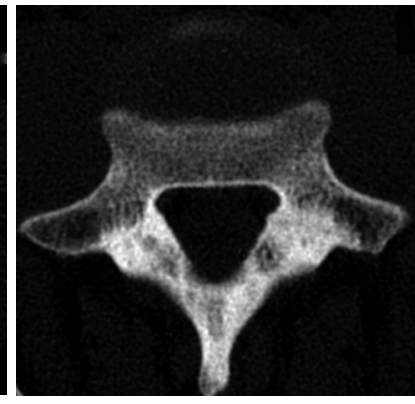

Fig. 2b
CT scans showing left unilateral spondylolysis a) before and b) after conservative treatment for three months.

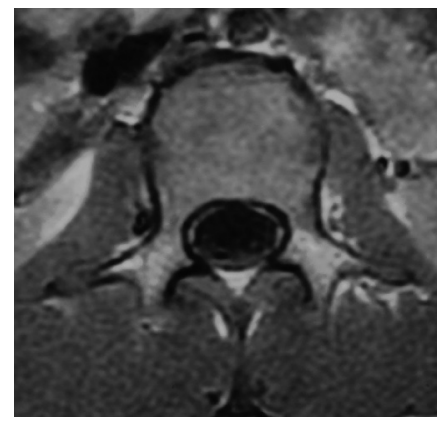

Fig. 3a

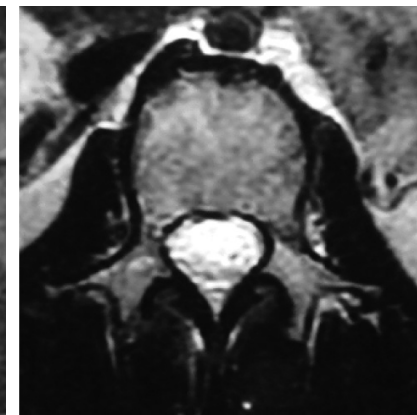

Fig. 3b
MR scans of the normal pedicle showing a) a T1- and b) a T2-weighted image. The signal in the pedicle is the same as that in the vertebral body.

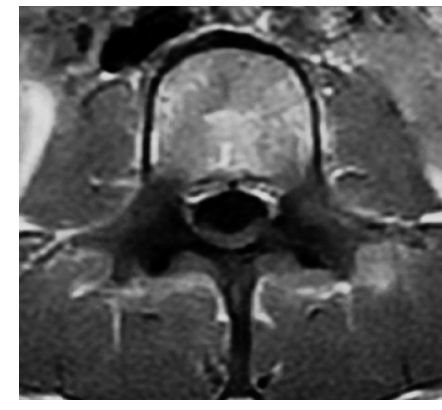

Fig. 4a

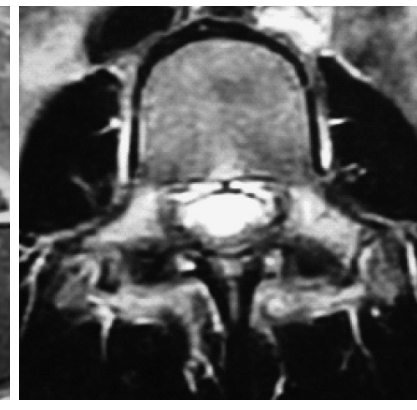

Fig. $4 b$
T1- (a) and T2- (b) weighted MR scans showing a high signal change. When the pedicle shows low signal intensity on the T1-weighted scan, the high signal change is taken as being positive.

early stage defect on CT and the existence of high signal change in the adjacent pedicle, on a T2-weighted MR scan were found to be good predictors of bony union.

Based on our results, we suggest a strategy for the conservative treatment of lumbar spondylolysis as shown in Figure 5. A good candidate for conservative treatment should have an early-stage defect on CT or a progressivestage defect on CT with high signal change of the adjacent pedicle on MRI. These patients should refrain from sports and wear a soft thoracolumbosacral brace. 


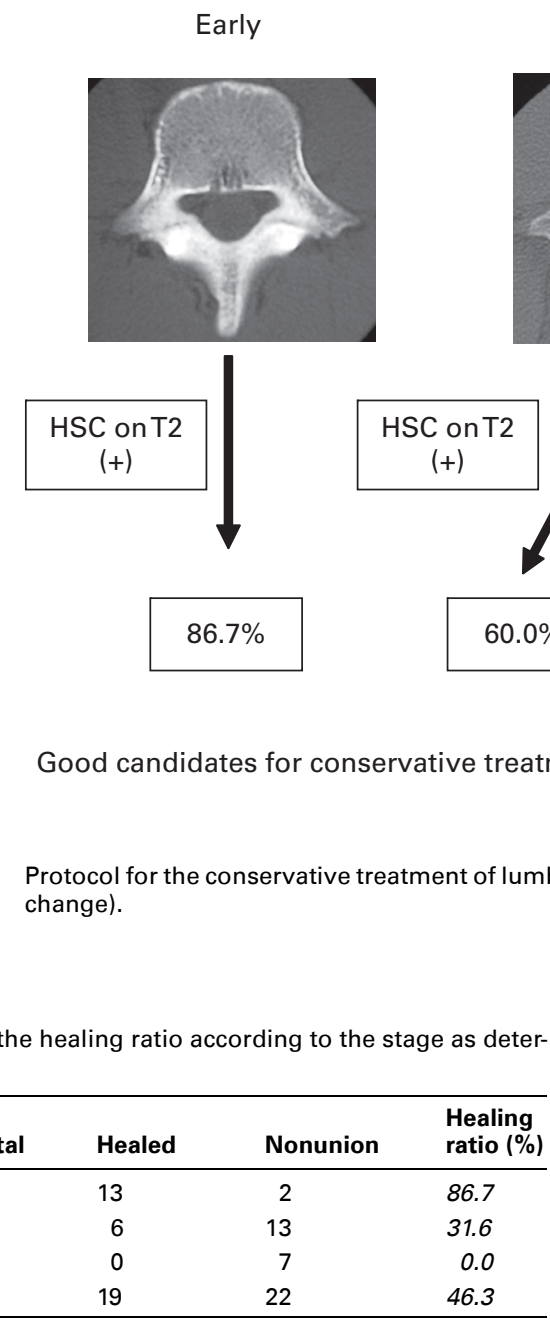

Table I. Details of the healing ratio according to the stage as determined by CT

\begin{tabular}{lcccc}
\hline Stage & Total & Healed & Nonunion & $\begin{array}{l}\text { Healing } \\
\text { ratio (\%) }\end{array}$ \\
\hline Early & 15 & 13 & 2 & 86.7 \\
Progressive & 19 & 6 & 13 & 31.6 \\
Terminal & 7 & 0 & 7 & 0.0 \\
Total & 41 & 19 & 22 & 46.3 \\
\hline
\end{tabular}

Table II. Details of the healing ratio according to the positive high signal change (HSC) of the adjacent pedicle on T2-weighted MRI

\begin{tabular}{llccc}
\hline HSC & Total & Healed & Nonunion & Healing ratio (\%) \\
\hline Positive & 26 & 20 & 6 & 76.9 \\
Negative & 15 & 0 & 15 & 0.0 \\
Total & 41 & 20 & 21 & 48.8 \\
\hline
\end{tabular}

For all other types of defect, there is little point in attempting to achieve bony union by conservative means. The aim of treatment in these patients should be to control low back pain. If this is severe, analgesics should be given in addition to the wearing of the brace. These patients do not need to refrain from sporting activities, but the treating surgeon should always be aware of the possibility of a progressive slip. ${ }^{7-9}$ Recent studies have shown that this occurs through the growth plate rather than the disc, ${ }^{10-17}$ particularly in children, because it is principally a disorder of the growth plate. We have previously shown that in
Progressive
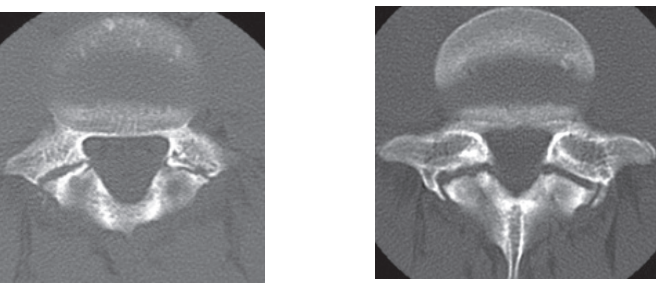

$(-)$

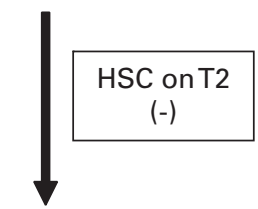

$0 \%$

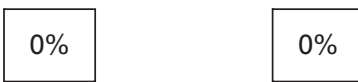

Pain management only

Fig. 5
Table III. Healing ratio according to the $\mathrm{CT}$ stage and high signal change (HSC) on MRI

\begin{tabular}{llll}
\hline CT stage & HSC on MRI & Number of cases & Healing ratio (\%) \\
\hline Early & $(+)$ & 15 & 86.7 \\
& $(-)$ & 0 & $\mathrm{~N} / \mathrm{A}^{*}$ \\
Progressive & $(+)$ & 10 & 60.0 \\
& $(-)$ & 9 & 0.0 \\
Terminal & $(+)$ & 0 & $\mathrm{~N} / \mathrm{A}$ \\
& $(-)$ & 7 & 0.0 \\
\hline * N/A, not available & &
\end{tabular}

$80 \%$ of children with an immature skeleton and a spondylolysis the slip increases within two years. ${ }^{8}$ This group should be observed carefully until they achieve skeletal maturity.

Sys et $\mathrm{al}^{6}$ have shown that isotope bone scanning can help to diagnose active spondylolysis which may heal without surgery. In our study, we chose not to carry out bone scanning. CT was needed to assess whether or not the pars defect had healed after treatment and we had no wish to expose our patients to excessive radiation. Instead, we used MRI and, as we have shown, even without the information obtained from a bone scan we were able to predict which lesions would heal.

All the patients in our study were Japanese. It is well recognised that there is a genetic predisposition to spondylolysis ${ }^{18-20}$ and its incidence differs among races. Our results, therefore may only be relevant for the Japanese 
population and we hope that our study will be replicated for other ethnic groups.

In conclusion, an early-stage defect on CT with high signal change in the adjacent pedicle on T2-negative MR scan will correctly predict healing of a pars defect after conservative treatment.

No benefits in any form have been received or will be received from a commercial party related directly or indirectly to the subject of this article.

\section{References}

1. Sairyo K, Katoh S, Sakamaki T, et al. Three successive stress fractures at the same verebral level in an adolescent baseball player. Am J Sports Med 2003;31:606-10.

2. Sairyo K, Katoh S, Sasa T, et al. Athletes with unilateral spondylolysis are at risk of stress fracture at the contralateral pedicle and pars interarticularis: a clinical and biomechanical study. Am J Sports Med 2005;33:583-90.

3. Wiltse LL, Widell EH Jr, Jackson DW. Fatigue fracture: the basic lesion is isthmic spondylolisthesis. J Bone Joint Surg [Am] 1975;57-A:17-22.

4. Fujii K, Katoh S, Sairyo K, Ikata T, Yosui N. Union of defects in the pars interarticularis of the lumbar spine in children and adolescents: the radiological outcome after conservative treatment. J Bone Joint Surg [Br] 2004;86-B:225-31.

5. Sairyo K, Katoh S, Takata Y, et al. MRI signal changes of the pedicle as an indicator for early diagnosis of spondylolysis in children and adolescents: a clinical and biomechanical study. Spine 2006;31:206-11.

6. Sys J, Michielsen J, Bracke P, Martens M, Verstreken J. Nonoperative treatment of active spondylolysis in elite athletes with normal X-ray findings: literature review and results of conservative treatment. Eur Spine J 2001;10:498-504.

7. Fredrickson BE, Baker D, McHolick WJ, Yuan HA, Lubicky JP. The natural history of spondylolysis and spondylolisthesis. J Bone Joint Surg [Am] 1984;66-A:699-707.

8. Sairyo K, Katoh S, Ikata T, et al. Development of spondylolytic olisthesis in adolescents. Spine 2001;1:171-5.
9. Seitsalo S, Österman K, Hyvärinen H, et al. Progression of spondylolisthesis in children and adolescents: a long-term follow-up of 272 patients. Spine 1991;16:417-21.

10. Higashino K, Sairyo K, Sakamaki T, et al. Vertebral rounding deformity in pediatric spondylolisthesis occurs due to deficient of endochonral ossification of the growth plate: radiological, histological and immunohistochemical analysis of a rat spondylolisthesis model. Spine 2007;32:2839-45.

11. Kajiura K, Katoh S, Sairyo K, et al. Slippage mechanism of pediatric spondylolysis: biomechanical study using immature calf spines. Spine 2001;26:2208-12.

12. Komatsubara S, Sairyo K, Katoh S, et al. High-grade slippage of the lumbar spine in a rat model of spondylolisthesis: effects of cyclooxygenase-2 inhibitor on its deformity. Spine 2006;31:528-34.

13. Konz RJ, Goel VK, Grobler LJ, et al. The pathomechanism of spondylolytic spondylolisthesis in immature primate lumbar spines in vitro and finite element assessments. Spine 2001;26:38-49.

14. Sairyo K, Goel VK, Grobler LJ, Ikata T, Katoh S. The pathomechanism of isthmic lumbar spondylolisthesis: a biomechanical study in immature calf spines. Spine 1998;23:1442-6.

15. Sairyo K, Katoh S, Sakamaki T, et al. Vertebral forward slippage in immature lum bar spine occurs following epiphyseal separation and its occurrence is unrelated to disc degeneration: is the pediatric spondylolisthesia physis stress fracture of vertebral body? Spine 2004;29:524-7.

16. Sairyo K, Goel VK, Masuda A, et al. Three-dimensional finite element analysis of the pediatric lumbar spine. Part II: biomechanical change as the initiating factor for pediatric isthmic spondylolisthesis at the growth plate. Eur Spine J 2006;15:930-5.

17. Sakamaki T, Sairyo K, Katoh S, et al. The pathogenesis of slippage and deformity in the pediatric lumbar spine: a radiographic and histologic study using a new rat in vivo model. Spine 2003;28:645-50.

18. Wiltse LL. Etiology of spondylolisthesis. Clin Orthop 1957;10:48-60.

19. Wiltse LL. The etiology of spondylolisthesis. J Bone Joint Surg [Am] 1962;44A:539-60.

20. Simper LB. Spondylolysis in Eskimo skeletons. Acta Orthop Scand 1986;57:78-80. 